\title{
Emergency Medical Technician
}

National Cancer Institute

\section{Source}

National Cancer Institute. Emergency Medical Technician. NCI Thesaurus. Code C53417.

A person with formal training in basic medical knowledge and skills, certified

(requirements vary by state) to respond and to provide a competent prehospital care and transportation to patients in emergency situations including but not limited to medical emergencies, hazardous materials exposure, child birth, abuse, fires, flood, accidents, trauma, and psychiatric crises. 